\title{
Phase II study of SPI-77 (sterically stabilised liposomal cisplatin) in advanced non-small-cell lung cancer
}

\author{
SC White*, , P Lorigan², GP Margison', JM Margison³, F Martin', N Thatcher', H Anderson' and M Ranson'

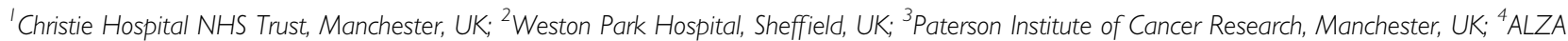 \\ Pharmaceuticals, Mountain View, CA, USA
}

To determine the efficacy and tolerability of SPI-77 (sterically stabilised liposomal cisplatin) at three dose levels in patients with advanced non-small-cell lung cancer (NSCLC). Patients had Stage IIIB or IV NSCLC and were chemo-naïve, and Eastern Oncology Cooperative Group 0-2. The first cohort received SPI-77 at $100 \mathrm{mg} \mathrm{m}^{-2}$, the second $200 \mathrm{mg} \mathrm{m}^{-2}$ and the final cohort $260 \mathrm{mg} \mathrm{m}{ }^{-2}$. Patients had also pharmacokinetics and analysis of leucocyte platinum (Pt)-DNA adducts performed. Twenty-six patients were treated, with 22 patients being evaluable for response. Only one response occurred at the $200 \mathrm{mg} \mathrm{m}^{-2}$ dose level for an overall response rate of $4.5 \%\left(7.1 \%\right.$ at $\left.\geqslant 200 \mathrm{mg} \mathrm{m}^{-2}\right)$. No significant toxicity was noted including nephrotoxicity or ototoxicity aside from two patients with Grade 3 nausea. No routine antiemetics or hydration was used. The pharmacokinetic profile of SPI-77 was typical for a liposomally formulated drug, and the AUC appeared to be proportional to the dose of SPI-77. Plasma Pt levels and leucocyte DNA adduct levels did not appear to rise with successive doses. SPI-77 demonstrates only modest activity in patients with NSCLC. British Journal of Cancer (2006) 95, 822-828. doi:I0.1038/sj.bjc.6603345 www.bjcancer.com

Published online 12 September 2006

(c) 2006 Cancer Research UK

Keywords: NSCLC; SPI-77; liposomes; cisplatin

One of the principal aims of anticancer drug development is to improve efficacy and reduce toxicity through greater tumour specificity. Liposomal formulations of drugs have long held promise as a drug vehicle. Initial difficulties of a rapid clearance of liposomes from the circulation by the macrophages of the reticulo-endothelial system were resolved with the development of sterically stabilised liposomes. Through the addition of methoxypolyethylene glycol moieties on the lipid bilayer surface, these sterically stabilised (or STEALTH ${ }^{\circledR}$ ) liposomes demonstrated prolonged circulation times.

Liposomes have several theoretical benefits that make them attractive as vehicles for anticancer agents. Through encapsulation of the cytotoxic agent, they reduce the potential for side effects resultant from free circulating drug (Ranson et al, 1997). Another theoretical advantage of liposomes is their preferential accumulation in the tumour interstitium rather than the microenvironment of healthy tissues. This phenomenon may be due to the passive movement of liposomes through the walls of 'leaky' tumour vasculature (Ogihara Umeda et al, 1996). This has ultimately translated into the development of liposome-encapsulated cytotoxic agents with demonstrated activity (Ranson et al, 1997; Fossa et al, 1998).

Cisplatin has been demonstrated to impact positively on survival in advanced non-small-cell lung cancer (NSCLC) (1995), but a downside is substantial systemic toxicity. Liposomal

\footnotetext{
*Correspondence: Dr SC White, Ludwig Department of Oncology, Austin Hospital, Studley Road, Heidelberg 3084, Australia;

E-mail: shane.white@austin.org.au

Received 31 May 2006; revised 9 August 2006; accepted 9 August 2006; published online 12 September 2006
}

encapsulation of cisplatin has the attraction of potentially reduced toxicity, as well as the potential for tumour targeting. ALZA Pharmaceuticals ${ }^{\mathbb{R}}$ (Mountain View, CA, USA; formerly SEQUUS Pharmaceuticals) developed a STEALTH ${ }^{\circledR}$ (sterically stabilised) liposomal formulation of cisplatin (SPI-77) that showed promising results in preclinical models, with significantly greater tumour growth delay than cisplatin. In subsequent phase I studies, the dose was escalated to $320 \mathrm{mg} \mathrm{m}^{-2}$ with the dose-limiting toxicity (DLT) of severe proximal myopathy (Meerum Terwogt et al, 2002).

In this study, chemo-naive patients with advanced NSCLC were treated with SPI-77 at different dose levels, with the primary end points of response and toxicity, and the secondary end points of survival.

\section{MATERIALS AND METHODS}

\section{Patient selection}

Eligible patients were required to have histologically or cytologically documented Stage IIIB or IV NSCLC deemed not amenable to therapy with curative intent. Patients were required to be chemonaive, have measurable disease, Eastern Oncology Cooperative Group (ECOG) performance status of $0-2,24 \mathrm{~h}$ creatinine clearance $\geqslant 50 \mathrm{ml} \mathrm{min}^{-1}$, adequate bone marrow reserve $\left(\mathrm{Hb} \geqslant 10.0 \mathrm{~g} \mathrm{dl}^{-1}\right.$, neutrophils $\geqslant 1500 \mathrm{~mm}^{-3}$, platelets $\left.\geqslant 100000 \mathrm{~mm}^{-3}\right)$ and adequate hepatic function (serum bilirubin $\leqslant 34 \mu \mathrm{moll}^{-1}$, transaminases $\leqslant 2$ times ULN). Specific exclusion criteria included clinically significant neuropathy or hearing loss.

All patients gave informed, written consent and the trial was approved by the local research ethics committee and conducted in accordance with good clinical practice obligations. 


\section{Treatment schedule}

The first cohort of patients received SPI-77 at a dose of $100 \mathrm{mg} \mathrm{m}^{-2}$ every 3 weeks. The second group received SPI-77 at $200 \mathrm{mg} \mathrm{m}^{-2}$ and the third group received $260 \mathrm{mg} \mathrm{m}^{-2}$. The initial dose level was chosen as an acceptable standard dose of cisplatin, and the final dose level was based on the maximum tolerated dose in the phase I study. SPI77 was administered as an intravenous (i.v.) infusion over $1 \mathrm{~h}$. No routine premedication or antiemesis was given. No additional hydration or diuresis was given. Patients received up to six cycles of treatment in the absence of unacceptable toxicity or disease progression.

\section{Assessment of response and toxicity}

At baseline, patients were assessed with a physical examination (including a meticulous neurological examination), an audiogram and assessment of renal function with calculated or measured $24 \mathrm{~h}$ creatinine clearance, and a ${ }^{51} \mathrm{Cr}$-EDTA isotopic GFR scan. Serum chemistry and electrolytes, liver function tests, lipid profile and full blood count was tested.

At cycle completion, reassessment included measured $24 \mathrm{~h}$ creatinine clearance, serum chemistry, full blood count and urinalysis. At treatment completion, patients were additionally assessed with audiometry and isotopic GFR scan.

Disease status was assessed at the beginning of treatment and after every other cycle, with either radiological examination (chest radiograph, computer tomography scan) or physical examination. Response was assessed according to standard World Health Organisation (WHO) criteria. Toxicities were graded according to National Cancer Institute (NCI) common toxicity criteria (CTC version 2).

\section{Statistical analysis}

Patients who met all eligibility criteria and received $\geqslant 2$ cycles were included in response assessment. Fifteen patients were planned to enter the study, with consideration to recruiting 10 extra patients if one or more responses occurred. The primary study end points were response rate and toxicity, with the secondary end points of overall survival and time to progression. Time to progression was taken from date of first treatment to date of progression. Survival was calculated from date of first treatment to death.

\section{Pharmacokinetic analysis}

Pharmacokinetic sampling was performed predosing, at the end of the $2 \mathrm{~h}$ infusion, $1,3,5,24,48,72,96 \mathrm{~h}$ postinfusion completion and on days 8,15 of cycle 1 . During subsequent cycles, samples were collected predosing, at infusion completion and at days 8, 15 and 22. At each blood sampling, $5 \mathrm{ml}$ of whole blood was drawn into a heparinised tube. The blood was centrifuged for $10 \mathrm{~min}$ at $4^{\circ} \mathrm{C}$. Plasma $(800 \mu \mathrm{l})$ was removed and added to $7.2 \mathrm{ml}$ of $0.1 \%$ Triton X-100 containing $0.2 \% \mathrm{HNO}_{3}$. The samples were divided into eight $1.0 \mathrm{ml}$ aliquots and stored at $-20^{\circ} \mathrm{C}$. The remaining plasma was ultrafiltered using an Amicon Centrifree ultrafiltration device by centrifugation at $1500 \mathrm{~g}$ for approximately $30 \mathrm{~min}$ using a fixed angle rotor. The ultrafiltrate was stored at $-20^{\circ} \mathrm{C}$.

Data analysis was performed using ABBOTTBASE ${ }^{\circledR}$ pharmacokinetic systems software.

Each patient's data were analysed by nonlinear least squares regression to determine the individual pharmacokinetic parameters. This utilises iterative nonlinear regression analysis to determine a set of pharmacokinetic parameters that measures $\phi$, a target objective function. Data from all patients was best fit by a 1compartment linear model.
AUC extrapolated to infinity (AUC $0-\infty$ ) was calculated as the sum of AUC $(0-t)$ and $C_{\text {pred }} / \lambda z$, where $C_{\text {pred }}$ is the predicted concentration at time $t$. The apparent terminal elimination rate constant $(\lambda z)$ was derived from the log-linear disposition phase of the concentration time curve using least squares regression analysis, with visual inspection of the data to determine the appropriate number of data points to include in the calculation of $\lambda z$. The apparent terminal elimination half-life $\left(t_{1 / 2}\right)$ was calculated as $\ln 2 / \lambda z$. The AUC calculations were derived from nonlinear least curves and uniform time/concentration combinations. In eight patients $(30.7 \%)$ out of 26 patients, data from ultrafiltrates were analysed for free platinum (Pt) and this was expressed as a percentage of total Pt.

\section{Peripheral blood mononuclear cell preparation}

An additional $20 \mathrm{ml}$ of whole blood from study participants was obtained for peripheral blood mononuclear cells.

Two $10 \mathrm{ml}$ blood samples were layered with a pipette onto an equivalent volume of Ficoll ${ }^{\mathbb{B}}$ (GE Healthcare, Uppsala, Sweden) in universal tubes. The tubes were centrifuged at $400 \mathrm{~g}$ for $30 \mathrm{~min}$ at $18-20^{\circ} \mathrm{C}$. The formed lymphocyte layer was transferred by pipette to another tube, and washed with PBS by centrifugation at $100 \mathrm{~g}$ for $10 \mathrm{~min}$ at $18-20^{\circ} \mathrm{C}$. A further wash took place before the cells were stored at $-80^{\circ} \mathrm{C}$.

\section{DNA isolation}

Tissue samples were thawed to room temperature in a microcentrifuge tube and $600 \mu \mathrm{l}$ of nuclei lysis buffer (Promega ${ }^{\mathbb{R}}$, Southampton, UK) (12 $\mathrm{ml} 0.5 \%$ EDTA:50 $\mathrm{ml}$ of lysis buffer). Proteinase K (Sigma, $17.5 \mu \mathrm{l}$ of a $20 \mathrm{mg} \mathrm{ml}^{-1}$ solution in $\mathrm{ddH}_{2} \mathrm{O}$ ) was added and samples were incubated overnight at $55^{\circ} \mathrm{C}$ with gentle shaking.

After digestion, $200 \mu \mathrm{l}$ of protein precipitation solution (Promega) was added to the microcentrifuge tube and samples were vortexed for $20 \mathrm{~s}$. Specimens were placed on ice for $5 \mathrm{~min}$ and then centrifuged at 15000 r.p.m. for $5 \mathrm{~min}$ at $4{ }^{\circ} \mathrm{C}$.

Supernatant $(700 \mu \mathrm{l})$ from each tube was aspirated and added to $800 \mu \mathrm{l}$ of isopropanol in a separate tube. Samples were inverted several times until a DNA mass formed. The specimens were centrifuged at 15000 r.p.m. for $2 \mathrm{~min}$ at $4^{\circ} \mathrm{C}$. The supernatant was discarded and the DNA pellet was washed with $600 \mu \mathrm{l}$ of $70 \%$ ethanol. Specimens were again centrifuged at 15000 r.p.m. for $2 \mathrm{~min}$ at $4^{\circ} \mathrm{C}$. Once more, the supernatant was discarded and the specimens were allowed to air dry for at least $15 \mathrm{~min}$. Samples were subsequently rehydrated with $100 \mu$ l of distilled $\mathrm{H}_{2} \mathrm{O}$. Specimens were incubated at $65^{\circ} \mathrm{C}$ for $1 \mathrm{~h}$ with regular mixing. All samples were then sonicated to ensure homogeneity and stored at $-20^{\circ} \mathrm{C}$ until analysed.

\section{DNA quantification}

Two $10 \mu \mathrm{l}$ aliquots of the $0,5,10,15,20,25,37.5$ and $50 \mu \mathrm{g} \mathrm{ml}^{-1}$ calf thymus DNA (Sigma) standards were placed in wells of a $96-$ well microtitre plate.

An aliquot of the sample to be analysed was diluted with appropriate volumes of Buffer I and vortex-mixed. Ten microlitres of the diluted sample was placed in each of two wells on the microtitre plate. Hundred microlitres of Hoechst dye solution

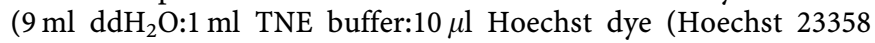
(Polyscience, Niles, Illinois, USA))) was added to each well. Fluorescence was measured using an FL500 fluorescence microtitre plate reader and DNA concentrations were extrapolated from the standard curve. The DNA concentration of each sample was then corrected for the original dilution. Duplicate values varied by no more than $5 \%$. 


\section{Platinum quantification}

Pt analysis was carried out by inductively coupled plasma mass spectrometry (ICP-MS), using a standard Plasma-Quad II instrument (VG Elemental, Winsford, UK), fitted with a standard autosampler and concentric nebuliser, using a method based on that developed by Christodoulou et al (1996). Solutions were prepared in $0.1 \mathrm{~m}$ nitric acid (Aristar grade, Merck Scientific, West Drayton, UK), and the assay was calibrated against Pt-containing solutions prepared by serial dilution from a certified reference standard. Measurements were made at the two highest abundance isotopic mass numbers, $194(32.9 \%)$ and 195 (33.8\%). The calibration was linear (typical $\mathrm{CV}<2 \%$ ) over the analytical working range $\left(0.01-100.0 \mu \mathrm{g} \mathrm{dm}^{-3}\right)$. The Pt-blank reading, obtained from the $0.1 \mathrm{M}$ nitric acid stock solution was subtracted from sample measurements, and in most cases was below $1 \%$ of the sample measurement. Procedural blanks were prepared alongside samples to test for inadvertent problems of contamination, but none were detected.

Solutions were diluted gravimetrically in acid-rinsed polyethylene bottles. Blood plasma was generally diluted 20 -fold with $0.1 \mathrm{M}$ nitric acid, and for samples with high Pt levels, greater dilution factors were employed as necessary to bring the Pt concentration within the working range. DNA solutions were resuspended in $0.1 \mathrm{M}$ nitric acid $(10 \mathrm{ml})$ before direct aspiration into the ICP-MS. In all cases, uniformity of analytical response was established by the method of additions. The estimated analytical precision was $< \pm 10 \%$, except for the DNA samples where the very low Pt concentrations resulted in a lower precision of measurement, estimated at $\sim 20 \%$.

\section{RESULTS}

\section{Patient characteristics}

Twenty-six patients entered the study at the Christie Hospital, Manchester and Weston Park Hospital, Sheffield between March 1998 and June 1999. Patient characteristics are listed in Table 1. A total of $57.7 \%$ of patients were male and the median age was 61.5

Table I Patient's characteristics $(n=26)$

\begin{tabular}{|c|c|c|}
\hline & No. & $\%$ \\
\hline Total & 26 & \\
\hline \multicolumn{3}{|l|}{ Sex } \\
\hline Male & 15 & 57.7 \\
\hline Female & $\mid 1$ & 42.3 \\
\hline \multicolumn{3}{|l|}{ Age (years) } \\
\hline Median & 61.5 & \\
\hline Range & $45-76$ & \\
\hline \multicolumn{3}{|l|}{ Histology } \\
\hline Adeno & 6 & 23 \\
\hline Squamous & 14 & 54 \\
\hline Large & 3 & 12 \\
\hline Other & 3 & 12 \\
\hline \multicolumn{3}{|c|}{ Performance status (ECOG) } \\
\hline 0 & 0 & 0 \\
\hline I & 19 & 73.1 \\
\hline 2 & 7 & 26.9 \\
\hline \multicolumn{3}{|l|}{ Disease stage } \\
\hline IIIA & 2 & 7.7 \\
\hline IIIB & 15 & 57.7 \\
\hline IV & 9 & 34.6 \\
\hline
\end{tabular}

$\mathrm{ECOG}=$ Eastern Oncology Cooperative Group. years (range $45-76$ years). Out of 26 patients, 19 patients $(73 \%)$ had a performance status of 1 , and nine patients $(35 \%)$ had evidence of metastatic disease.

\section{Chemotherapy administration}

The 26 patients received a total of 100 cycles with a median number of 3.5 cycles. Nine patients received SPI-77 at $100 \mathrm{mg} \mathrm{m}^{-2}$ for a total of 31 cycles (median three cycles); 12 patients received treatment at $200 \mathrm{mg} \mathrm{m}^{-2}$ for a total of 48 cycles (median four cycles); and five patients received treatment at $260 \mathrm{mg} \mathrm{m}^{-2}$ for a total of 21 cycles (median four cycles). Only one patient received a dose delay (of 1 week), owing to a falsely low creatinine clearance result. No patients received a dose reduction.

\section{Response and survival}

Patients who fully met the entry criteria and who received and completed at least two cycles of therapy were evaluable for response and survival according to the protocol. Four patients were not assessable for tumour response. Two patients had Stage IIIA disease, one patient did not have the required histological confirmation, and one patient died of early progression, having received only one cycle.

No objective responses occurred at the $100 \mathrm{mg} \mathrm{m}^{-2}$ dose level. One patient achieved a partial response at the $200 \mathrm{mg} \mathrm{m}^{-2}$ dose level. The duration of the response was 63 days. No additional responses occurred in the $260 \mathrm{mg} \mathrm{m}^{-2}$ group. Two patients experienced a minor response; one patient at $100 \mathrm{mg} \mathrm{m}^{-2}$ and another at $200 \mathrm{mg} \mathrm{m}^{-2}$. The response rate was $0 \%(0$ patient out of eight evaluable patients) at $100 \mathrm{mg} \mathrm{m}^{-2}$ and $10 \%$ at $200 \mathrm{mg} \mathrm{m}^{-2}$ (one patient out of 10 evaluable patients). There were no further responses at the $260 \mathrm{mg} \mathrm{m}^{-2}$ so the response rate was $7.1 \%$ at doses of $\geqslant 200 \mathrm{mg}$ (one patient out of 14 evaluable patients).

Median time to progression was 12 weeks. Median overall survival was 23 weeks (range: 3.6-90.4 weeks).

Seven patients $(27 \%)$ received second-line cisplatin-based combination chemotherapy. One response was seen, four patients had stable disease, and two patients progressed through treatment.

\section{Toxicity}

SPI-77 was extremely well tolerated at the administered schedule. No significant myelosuppression occurred with the maximum toxicity being Grade 2 anaemia in $30 \%$ of patients. Three of the 26 patients required at least one blood transfusion (Table 2). Nonhaematological toxicities were generally mild and subjective tolerability was excellent (Table 3). Two patients suffered Grade 3 nausea and vomiting (7.7\%). Subsequent nausea was well controlled with the use of $5 \mathrm{HT}_{3}$ receptor antagonists. Otherwise, prophylactic antiemetics were not used routinely.

Four patients developed a mild rash (three erythematous maculopapular, one psoriaform). Four patients experienced itch (one episode of Grade 3 itch).

All study patients lacked a history of clinically significant deafness. All patients received baseline audiograms. Out of 26 patients, 15 patients $(57.7 \%)$ had abnormal audiograms of which 10 patients $(67 \%)$ out of 15 patients had age-related high frequency loss bilaterally, and five patients $(33 \%)$ out of 15 patients had moderate-severe sensori-neural loss bilaterally. Sixteen patients had follow-up audiograms although 13 of these were abnormal at baseline. Only one patient out of 16 patients had a significant change, with a 40 decibel $(\mathrm{dB})$ hearing loss at $2000 \mathrm{~Hz}$ in one ear, having had moderate to severe high frequency loss at baseline. Another patient was noted to a have a slight deterioration in acuity at $4000-8000 \mathrm{~Hz}$, on a background of moderate high frequency loss at baseline. The median cumulative dose of cisplatin received by the 16 patients was $600 \mathrm{mg} \mathrm{m}^{-2}$. 
All patients underwent a lower limb assessment of peripheral nerves, testing pinprick sensation, proprioception, vibration and deep tendon reflexes, at baseline and following each cycle. No changes in clinical signs occurred in any patients over the course of treatment.

Patients were assessed pretreatment and at the end of each cycle with either a measured or calculated creatinine clearance. The mean GFR by ${ }^{51} \mathrm{Cr}$-EDTA at baseline for the 26 patients was $80.6 \mathrm{ml} \mathrm{min}^{-1}$ (median $90.23 \mathrm{ml} \mathrm{min}^{-1}$, range $55-166 \mathrm{ml} \mathrm{min}^{-1}$ ). At the end of treatment, out of 26 patients, 17 patients $(65.4 \%)$ also had a follow-up ${ }^{51} \mathrm{Cr}$-EDTA isotopic GFR scan. The mean $\%$ change in GFR following treatment was $-2.16 \%$ (median $+1.3 \%$, range -27.4 to $+20 \%$ ). The remainder of the group was assessed with a measured or calculated creatinine clearance, with no significant change seen from baseline.

Table 2 Toxicity (haematological and nonhaematological) $(n=26)$

\begin{tabular}{|c|c|c|}
\hline Toxicity & No. & $\%$ \\
\hline \multicolumn{3}{|c|}{ Thrombocytopenia } \\
\hline Grade I/2 & - & - \\
\hline Grade 3/4 & - & - \\
\hline \multicolumn{3}{|l|}{ Neutropenia } \\
\hline Grade I/2 & 1 & 3.8 \\
\hline Grade 3/4 & - & - \\
\hline \multicolumn{3}{|l|}{ Anaemia } \\
\hline Grade I/2 & 21 & 81 \\
\hline Grade 3/4 & - & - \\
\hline \multicolumn{3}{|l|}{ Nausea } \\
\hline Grade I/2 & 10 & 38 \\
\hline Grade 3 & 2 & 7.7 \\
\hline \multicolumn{3}{|l|}{ Vomiting } \\
\hline Grade 1/2 & 5 & 19.2 \\
\hline Grade 3 & 2 & 7.7 \\
\hline \multicolumn{3}{|l|}{ Itch } \\
\hline Grade I/2 & 3 & 11.5 \\
\hline Grade 3 & I & 3.8 \\
\hline \multicolumn{3}{|l|}{ Febrile reaction } \\
\hline Grade I & 2 & 7.7 \\
\hline \multicolumn{3}{|l|}{ Rash } \\
\hline Grade 1/2 & 4 & 15.3 \\
\hline \multicolumn{3}{|l|}{ Taste } \\
\hline Grade 1/2 & 3 & 11.5 \\
\hline \multicolumn{3}{|l|}{ Tinnitus } \\
\hline Grade I/2 & I & 3.8 \\
\hline
\end{tabular}

\section{Pharmacokinetics}

One of the two treating centres participated in pharmacokinetic analysis of SPI-77, with data being obtained from 17 patients. A total of 710 samples from 355 time points were collected and analysed from the 17 patients. Nine patients were evaluated at the $100 \mathrm{mg} \mathrm{m}^{-2}$ dose level, six patients at $200 \mathrm{mg} \mathrm{m}^{-2}$ and two patients at $260 \mathrm{mg} \mathrm{m}^{-2}$.

The AUC of $\mathrm{Pt}$ (considered a reasonable surrogate for cisplatin/ SPI-77) over the first cycle $\left(\mathrm{AUC}_{1-22 \text { days }}\right)$ at the $100 \mathrm{mg} \mathrm{m}^{-2}$ dose

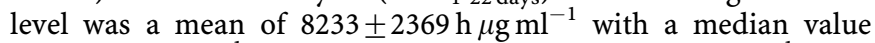

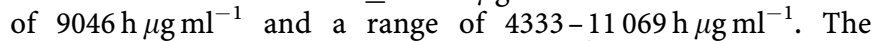
mean $\mathrm{AUC}_{1-22 \text { days }}$ at the $200 \mathrm{mg} \mathrm{m}^{-2}$ dose level was

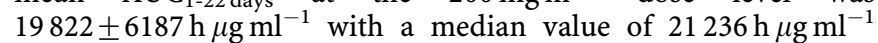
and a range of $10765-24139 \mathrm{~h} \mu \mathrm{g} \mathrm{ml}^{-1}$. The mean and median $\mathrm{AUC}_{1-22 \text { days }}$ at the $260 \mathrm{mg} \mathrm{m}^{-2}$ dose level was

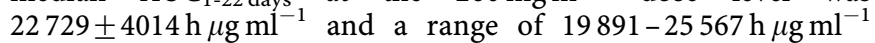
(Table 3). No significant accumulation of SPI-77 was noted in subsequent cycles and the AUCs for cycles 1 and 2 appeared similar at all dose levels (Figure 1 ). The mean $\mathrm{AUC}_{1-22 \text { days }} \mathrm{S}$ appeared to increase linearly with dose $\left(r^{2}=0.54\right)$.

Drug concentration declined in a mono-exponential way with a mean $t_{1 / 2}$ of $107.4 \pm 25.29 \mathrm{~h}$ (median $108 \mathrm{~h}$, range $62.3-168 \mathrm{~h}$ ) (Figure 2). Plasma clearance of SPI-77 had a mean of $0.02181 \mathrm{lh}^{-1}$ (median $0.01881 \mathrm{~h}^{-1}$, range $0.0099-0.0416 \mathrm{~h} \mathrm{~h}^{-1}$ ) and was independent of dose (Table 3). The apparent volume of distribution $\left(V_{\mathrm{d}}\right)$ had a mean of 3.1341 (median 3.24l, range 2.07-4.08l) that approximates to plasma volume, and was independent of dose.

Eight patients $(30.7 \%)$ were assessed for free (ultrafiltrated) Pt levels. These were universally very low, with a mean value of $0.139 \%$ of the corresponding total Pt (median $0.048 \%$, range 0.0015-1.1022\%). In two patients who were assessed for ultrafiltrated Pt levels over the first two cycles, the $C_{\max }$ occurred at days 3 and 4 with levels of $0.15-0.16 \mu \mathrm{g} \mathrm{ml}^{-1}$.

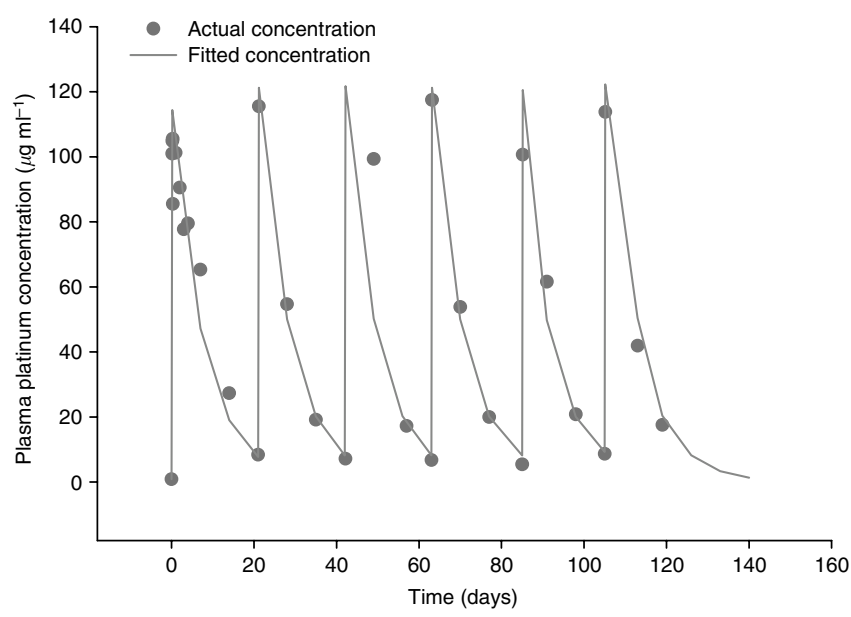

Figure I Plasma Pt concentration over time in patient 217, receiving SPI-77 $200 \mathrm{mg} \mathrm{m}^{-2}$ i.v. 3 weekly over six cycles.

Table 3 Pharmacokinetic parameters of patients treated with $100-260 \mathrm{mg} \mathrm{m}^{-2}$ SPI-77 i.v. during days I-22

\begin{tabular}{|c|c|c|c|c|c|c|c|c|}
\hline \multirow[b]{2}{*}{ Dose SPI-77 $\left(\mathrm{mg} \mathrm{m}^{-2}\right)$} & \multicolumn{2}{|c|}{$A \cup C_{1-22}\left(h \mu \mathrm{g} \mathrm{ml}^{-1}\right)$} & \multicolumn{2}{|c|}{ Clearance $\left(I^{-1}\right)$} & \multicolumn{2}{|c|}{$V_{d}(I)$} & \multicolumn{2}{|c|}{ Half-life (h) } \\
\hline & Mean & s.d. & Mean & s.d. & Mean & s.d. & Mean & s.d. \\
\hline 200 & 19822 & 6186 & 0.019 & 0.002 & 3.00 & 0.7 & 120.83 & 32.31 \\
\hline 260 & 22729 & 4013 & 0.022 & 0.004 & 3.2 & 0.06 & 103.95 & 17.04 \\
\hline
\end{tabular}

$\mathrm{AUC}=$ area under the curve; i.v. = intravenous; s.d. = standard deviation; $V_{d}=$ volume of distribution. 


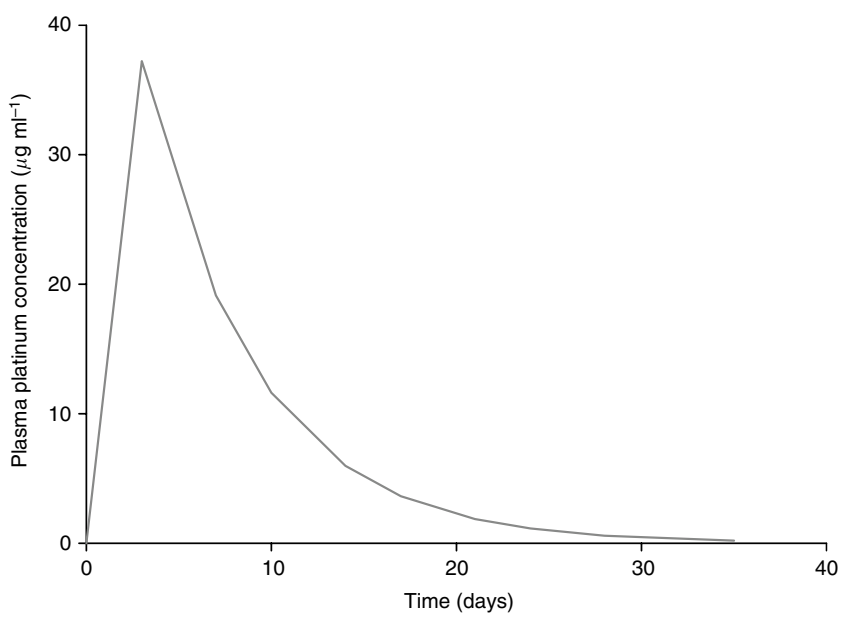

Figure 2 Population concentration over time curve for patients treated with $100 \mathrm{mg} \mathrm{m}^{-2} \mathrm{SPI}-77$ during cycle I.

Seventeen patients $(65.4 \%)$ had extra blood samples taken for lymphocyte collection. Cisplatin-DNA adducts were measured over the course of the first two cycles. At $100 \mathrm{mg} \mathrm{m}^{-2}$, the adduct levels peaked at $151 \pm 186 \mathrm{pg} \mathrm{Pt} \mu \mathrm{g}^{-1}$ DNA on day 4 of cycle 1 . A small rise in cisplatin-DNA adduct formation was seen again following the second cycle of SPI-77. The mean levels were lowest at day 1 of the second cycle $\left(18 \pm 11 \mathrm{pg}\right.$ Pt $\mu \mathrm{g}^{-1}$ DNA). There was no evidence of accumulation of adducts over time as they returned to pretreatment levels at the end of cycles 1 and 2 (Figure 3). There was no evidence of increased adduct formation when the dose was increased from 200 to $260 \mathrm{mg} \mathrm{m}^{-2}$.

\section{DISCUSSION}

The phase II study tested three different doses of SPI-77 to assess activity and toxicity of SPI-77 over an extended number of cycles. Cumulative toxicity is a common clinical problem with conventional cisplatin and has also been a significant problem with STEALTH ${ }^{\circledR}$ liposomal doxorubicin (Ranson et al, 1997). A total of 100 cycles of SPI-77 at $100-260 \mathrm{mg} \mathrm{m}^{-2}$ were administered to the 26 patients with a median of 3.5 cycles per patient. The experience at higher cumulative doses in the current trial was far greater than the initial phase I study where 21 patients were treated for a total of 59 cycles, at dose levels ranging from 40 to $320 \mathrm{mg} \mathrm{m}^{-2}$, at a median number of two cycles per patient (Meerum Terwogt et al, 2002).

The objective overall response rate of $4.5 \%$ to SPI-77 was disappointing, even for a single agent in NSCLC. No responses were seen at $100 \mathrm{mg} \mathrm{m}^{-2}$. If only patients treated at $\geqslant 200 \mathrm{mg} \mathrm{m}^{-2}$ were included in response analysis, the response rate was $7.1 \%$. This compares with the activity of single-agent cisplatin in advanced NSCLC of 6-32\% in various studies (Thatcher, 1995). The one patient who achieved an objective or partial response progressed by cycle 5 . Two other patients had minor responses to SPI-77. The median overall survival of 23 weeks was relatively short compared with the survival of patients treated with singleagent cisplatin in other recent studies (Wozniak et al, 1998; Sandler et al, 2000). Performance status plays an important role in influencing the duration of longer survival with treatment of advanced NSCLC (Thatcher et al, 1995). Given that the patients had relatively good performance status (with PS $\leqslant 1$ in $73.1 \%$ ), the disappointing survival in this phase II study would be consistent with SPI-77 having low activity as a single agent in advanced NSCLC.

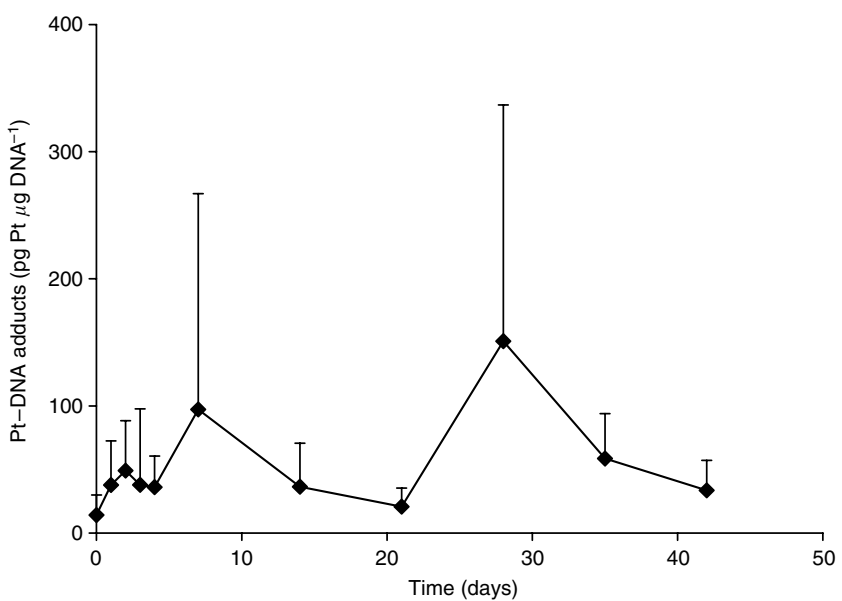

Figure 3 Pt-DNA adducts in patients receiving $100 \mathrm{mg} \mathrm{m}^{-2}$ SPI-77 i.v. 3weekly.

In contrast to the well-known potential consequences of conventional cisplatin such as nausea, myelosuppression, nephrotoxicity and neurotoxicity, SPI-77 was extremely well tolerated in all patients. Despite the extremely high $C_{\max }$ and AUC plasma levels of SPI-77, toxicities typical of conventional cisplatin were not seen. This underscores the ability of STEALTH ${ }^{\mathbb{R}}$ liposomes to reduce drug toxicity. In this study, myelosuppression was not clinically significant, with no instances of Grade 3/4 or thrombocytopenia. Mild anaemia was common with $31 \%$ of patients having Grade 2 anaemia although only three patients required a blood transfusion.

Nonhaematological toxicity was also mild with SPI-77. Grade 3/4 nausea occurred in $7.7 \%$ of patients, with no other requirement in the other patients for routine antiemetic treatment such as $5 \mathrm{HT}_{3}$ receptor antagonists. This is in contrast to the usual antiemetic protocols required with conventional cisplatin therapy. In the current study, there were instances of hypersensitivity reactions to SPI-77 during the infusion in two patients. Four patients had varying grades of itch, and four patients had a skin rash. None of the patients developed the type or severity of rash that is encountered with STEALTH ${ }^{\circledR}$ liposomal doxorubicin therapy (Ranson et al, 1997).

In the case of neurotoxicity, there was no evidence of clinically significant peripheral neuropathy. Additionally, none of the patients showed signs of a proximal myopathy, a feature that was reported in two patients treated at $320 \mathrm{mg} \mathrm{m}^{-2}$ in the phase I study of SPI-77 (Meerum Terwogt et al, 2002). Only one patient exhibited a change in audiometry with a $20 \mathrm{~dB}$ unilateral hearing loss. Although this loss occurred at the typical frequency of normal human speech, the patient concerned denied any tinnitus or subjective change in hearing. In contrast, a study that examined the ototoxicity of conventional cisplatin at doses of $50-$ $100 \mathrm{mg} \mathrm{m}^{-2}$ found that deterioration in audiometry post-therapy was frequent (Schaefer et al, 1985) with higher frequency loss $(4000-8000 \mathrm{~Hz})$ common at cumulative doses of $200 \mathrm{mg}$. The authors concluded that cisplatin ototoxicity was dose-dependent. Ototoxicity was not consistently seen with SPI-77 despite high cumulative Pt doses (median $600 \mathrm{mg} \mathrm{m}^{-2}$, range $200-$ $1560 \mathrm{mg} \mathrm{m}^{-2}$ ), suggesting that cisplatin neurotoxicity was considerably reduced with liposomal encapsulation

Nephrotoxicity was the DLT in the early studies of conventional cisplatin (Finley et al, 1985). In a previous study of conventional cisplatin, 15 patients who had received $100 \mathrm{mg} \mathrm{m}^{-2}$ every 3 weeks for a median of three cycles had a fall in creatinine clearance from $112 \mathrm{ml} \mathrm{min}^{-1}$ at baseline to $65 \mathrm{ml} \mathrm{min}^{-1}$ at treatment completion. 
However, GFR did not change significantly during the course of SPI-77 treatment. Additionally, aggressive hydration schedules are routinely used to reduce the incidence of cisplatin-induced acute renal dysfunction, whereas in this study, patients received no additional hydration or forced diuresis.

The data from the trial reported here have demonstrated that the toxicity profile of SPI-77 was markedly different from conventional cisplatin at either standard doses $\left(75-100 \mathrm{mg} \mathrm{m}^{-2}\right)$ or experimental high doses $\left(>100 \mathrm{mg} \mathrm{m}^{-2}\right)$. This reduced toxicity owing to liposomal encapsulation has been noted with other liposomeencapsulated cytotoxic agents such as Daunoxome ${ }^{\mathbb{B}}$ or Caelyx/ Doxil $^{\mathbb{R}}$ (Ranson et al, 1997; Fossa et al, 1998).

In the case of doxorubicin and cisplatin, side effects such as cardiomyopathy (doxorubicin) and nephrotoxicity (cisplatin) have been partly attributed to high levels of peak free drug (Minow et al, 1977; Nagai et al, 1986). In a study by Nagai et al (1986), the plasma $C_{\max }$ of ultrafiltrated Pt was the most useful pharmacokinetic marker for cisplatin nephrotoxicity. In our study, free cisplatin levels were extremely low in plasma, with a mean value of $0.09 \mu \mathrm{g} \mathrm{ml}^{-1}$. In the two patients who were assessed by determination of serial ultrafiltrated Pt levels, the peak Pt concentration of $0.15-0.16 \mu \mathrm{g} \mathrm{ml}^{-1}$ was 60 -fold lower than levels in patients postbolus treatment with $100 \mathrm{mg} \mathrm{m}^{-2}$ of conventional cisplatin in a previous study (Vermorken et al, 1982). In conclusion, the improved toxicity profile of SPI-77 was likely to be due to stable encapsulation of cisplatin by the liposomes, resulting in minimal free Pt in plasma.

The pharmacokinetics of SPI-77 was assessed in 17 of 26 patients enrolled in the trial. The plasma AUCs of Pt (considered a reasonable surrogate for cisplatin/SPI-77) levels were 100-fold higher than have been reported for conventional cisplatin at $100 \mathrm{mg} \mathrm{m}^{-2}$ (Johnsson et al, 1996). Plasma clearance of SPI-77 was lower, and $t_{1 / 2}$ longer compared to conventional cisplatin. $V_{\mathrm{d}}$ in SPI-77 was equivalent to plasma volume, in contrast to cisplatin that has a larger $V_{\mathrm{d}}$ of 11-24l (Andersson et al, 1996; Johnsson et al, 1996). Accordingly, the pharmacokinetic behaviour of SPI-77 follows the typical model of a STEALTH ${ }^{\mathbb{R}}$ liposome-encapsulated drug.

The levels of free Pt following SPI-77 were noted to be a minute fraction $(0.139 \%)$ of the total plasma Pt. It is unclear whether the free cisplatin appears in the plasma as a result of release of drug following degradation of the liposomes by the macrophagemonocyte system or whether the drug becomes bioavailable in plasma following breakdown of the liposomal membrane in the circulation.

Pt-DNA adduct formation was assessed in 17 of the patients with higher levels noted than previously seen in other studies of cisplatin-treated patients. As lymphocyte cisplatin-DNA adducts are presumed to arise from exposure in vivo to free cisplatin, lower levels of adducts might have been expected as a consequence of the extremely low plasma free Pt levels post-SPI-77 and this may be a result of carry-over of liposomal Pt during Ficoll separation of lymphocytes and release during later processing. Alternatively, it may be the result of enhanced exposure of lymphocytes to SPI-77 liposomes entrapped in the reticuloendothelial system sinusoids.

SPI-77 is a novel formulation of cisplatin, encapsulated in sterically stabilised liposomes. Its toxicity in humans is mild, with almost no evidence of Grade 3/4 haematological or nonhaematological toxicity. No significant toxicity peculiar to SPI-77 was noted, with only an occasional mild rash or infusion-related hypersensitivity reaction. This is contrast to palmar-plantar erythema that occurs with Caelyx/Doxil ${ }^{\mathbb{R}}$ SPI-77 was easily doseescalated to $260 \mathrm{mg} \mathrm{m}^{-2}$ and total cumulative doses of up to $1560 \mathrm{mg} \mathrm{m}^{-2}$ were administered without reaching acute or cumulative DLT.

Toxicity, mainly in the form of liver damage, hampered the execution of tumour xenograft experiments testing SPI-77
(Colbert, 1999). Interestingly, such toxicity was neither demonstrated in larger animals, nor in the present human studies. The interspecies differences in the tolerability of SPI-77 probably reflect differences in the metabolism of the acute lipid-loading inherent with SPI-77. A single published study and unpublished data from our group have demonstrated SPI-77 activity against a variety of tumour xenograft models (Newman et al, 1999). Tumour growth delay was significantly longer in tumour xenografts treated with SPI-77 in comparison to conventional cisplatin.

The promising activity of SPI-77 in the animal xenograft studies was not replicated in the clinical trial of patients with advanced NSCLC. In the current phase II study, the response rate was a modest $4.5 \%$. Similarly, no objective tumour responses occurred in the 24 patients in the phase I study (Meerum Terwogt et al, 2002), and also in another phase II study in a similar population (Kim et al, 2001). Three responses (out of 17 patients) were seen with a combination of SPI-77 and vinorelbine in a phase I study (Vokes et $a l, 2000)$. In patients with head and neck tumours, it has been administered safely with radiation, but as a single agent was disappointing with no responses (Harrington et al, 2001; Rosenthal et al, 2002).

The response rate in this phase II study of SPI-77 appears inferior to other known active single agents in NSCLC, including conventional cisplatin, carboplatin and newer agents such as gemcitabine (Thatcher et al, 1995). Despite the minimal toxicity of the drug, SPI-77's low activity in advanced NSCLC does not justify further clinical studies in this disease setting.

As significant antitumour activity was demonstrated in the xenograft experiments, the reason for low activity in human studies may relate to host differences or to differences between xenografts and de novo cancers in humans. Additionally, the ability to metabolise liposomal drugs is limited in rodents, yet such formulations are well tolerated by higher species including humans. It is therefore possible that drug metabolism may be relevant to the differences in efficacy of SPI-77 in animal xenografts compared to advanced NSCLC.

An alternative hypothesis for the lack of clear correlation between preclinical and clinical efficacy of SPI-77 may relate to the differences in tumours. The size, location and vascularity of the tumours differ between xenograft tumours in mice and human tumours. Differences in the degree of vascularity and vessel permeability may lead to altered rates of liposomal diffusion into the tumour interstitium. It is worth noting that to date the most sensitive and attractive disease setting for STEALTH ${ }^{\mathbb{R}}$ liposomal doxorubicin is the setting of Kaposi's sarcoma where high vessel density and permeability are features. One might therefore theorise that SPI-77 may also be more active in settings where high vascularity and permeability are present.

The demonstrated activity of SPI-77 in human tumour xenografts does not completely exclude an inherent problem of the formulation of the cisplatin. The markedly protracted plasma kinetics may mean that free drug delivery to tumours takes place at a slow rate, thereby allowing adducts to be more successfully repaired. Certainly, the low levels of ultrafiltrated Pt are suggestive of retention of cisplatin by the liposomes, and it may be that the liposomal encapsulation is too retentive a vehicle to allow release of free drug. In the phase I study, two patients were assessed for tumour levels of Pt-DNA adducts and these were found to be low. This again could reflect either poor tumour penetration by the liposomes or inadequate release of free drug (Meerum Terwogt et al, 2002).

Although SPI-77 did not demonstrate sufficient activity to merit further study in advanced NSCLC, the trial demonstrated that large doses of liposomal cisplatin can be administered safely and with little toxicity. If an improved formulation of liposomal cisplatin can enhance drug delivery to the site of the tumour, then an agent with good activity and minimal toxicity might be developed for clinical use. Effective tumour targeting may optimise the 
radiosensitisation effects in combined therapy protocols in advanced NSCLC. Its application may also be extended to other cancers that are responsive to cisplatin, such as ovarian, head and neck and oesophageal cancer.

\section{REFERENCES}

Andersson A, Fagerberg J, Lewensohn R, Ehrsson H (1996) Pharmacokinetics of cisplatin and its monohydrated complex in humans. J Pharm Sci 85: 824

Christodoulou J, Kashani M, Keohane BM, Sadler PJ (1996) Determination of gold and platinum in the presence of blood plasma proteins using inductively coupled plasma mass spectrometry. J Anal At Spectrom 11: $1031-1035$

Colbert G (1999) Personal Communication

Finley RS, Fortner CL, Grove WR (1985) Cisplatin nephrotoxicity: a summary of preventative interventions. Drug Intell Clin Pharm 19: $362-367$

Fossa SD, Aass N, Paro G (1998) A phase II study of DanoXome in advanced urothelial transitional cell carcinoma. Eur J Cancer 34: $1131-1132$

Harrington KJ, Lewanski CR, Northcote AD, Whittaker J, Wellbank H, Vile RG, Peters AM, Stewart JS (2001) Phase I-II study of pegylated liposomal cisplatin (SPI-077) in patients with inoperable head and neck cancer. Ann Oncol 12: 493-496

Johnsson A, Kjellen E, Wennerberg J, Pero R (1996) Metoclopramide as a modulator of cisplatin: effects on pharmacokinetcs and cisplatin-DNA adducts in tumor and normal tissue. Anticancer Drugs 7: $483-488$

Kim ES, Lu C, Khuri FR, Tonda M, Glisson BS, Liu D, Jung M, Hong WK, Herbst RS (2001) A phase II study of STEALTH cisplatin (SPI-77) in patients with advanced non-small cell lung cancer. Lung Cancer 34: $427-432$

Meerum Terwogt JM, Groenewegen G, Pluim D, Maliepaard M, Tibben MM, Huisman A, ten Bokkel Huinink WW, Schot M, Welbank H, Voest EE, Beijnen JH, Schellens JM (2002) Phase I and pharmacokinetic study of SPI-77, a liposomal encapsulated dosage form of cisplatin. Cancer Chemother Pharmacol 49: 201-210

Minow RA, Benjamin RS, Lee ET, Gottlieb JA (1977) Adriamycin cardiomyopathy - risk factors. Cancer 39: 1397-1402

Nagai N, Kinoshita M, Ogata H, Tsujino D, Wada Y, Someya K, Ohno T, Masuhara K, Tanaka Y, Kato K, Nagai H, Yokoyama A, Kurita Y (1986) Relationship between phamacokinetics of unchanged cisplatin and nephrotoxicity after intravenous infusions of cisplatin to cancer patients. Cancer Chemother Pharmacol 39: 131-137
Newman MS, Colbern GT, Working PK, Engbers C, Amantea MA (1999) Comparative pharmacokinetics, tissue distribution, and therapeutic effectiveness of cisplatin encapsulated in long-circulating, pegylated liposomes (SPI-077) in tumor-bearing mice. Cancer Chemother Pharmacol 43: $1-7$

Ogihara Umeda I, Sasaki T, Kojima S, Nishigori H (1996) Optimal radiolabeled liposomes for tumor imaging. J Nucl Med 37: 326-332

Ranson MR, Carmichael J, O'Byrne K, Stewart S, Smith D, Howell A (1997) Treatment of advanced breast cancer with sterically stabilized liposomal doxorubicin: results of a multicenter phase II trial [see comments]. J Clin Oncol 15: 3185-3191

Rosenthal DI, Yom SS, Liu L, Machtay M, Algazy K, Weber RS, Weinstein GS, Chalian AA, Mille LK, Rockwell Jr K, Tonda M, Schnipper E, Hershock D (2002) A phase I study of SPI-077 (stealth liposomal cisplatin) concurrent with radiation therapy for locally advanced head and neck cancer. Invest New Drugs 20: 343-349

Sandler AB, Nemunaitis J, Denham C, von Pawel J, Cormier Y, Gatzemeier U, Mattson K, Manegold C, Palmer MC, Gregor A, Nguyen B, Niyikiza C, Einhorn LH (2000) Phase III trial of gemcitabine plus cisplatin versus cisplatin alone in patients with locally advanced or metastatic non-smallcell lung cancer. J Clin Oncol 18: 122-130

Schaefer SD, Post JD, Close LG, Wright CG (1985) Ototoxicity of low- and moderate-dose cisplatin. Cancer 56: 1934-1939

Thatcher N, Ranson M, Lee SM, Niden R, Anderson H (1995) Chemotherapy in non small cell lung cancer. Ann Oncol 6: S83-S95

Vermorken JB, van der Vijgh WJ, Klein I, Gall HE, Pinedo HM (1982) Pharmacokinetics of free platinum species following rapid, 3-hr and 24$\mathrm{hr}$ infusions of cis-diamminedichloroplatinum (II) and its therapeutic implications. Eur J Cancer Clin Oncol 18: 1069-1074

Vokes EE, Gordon GS, Mauer AM, Rudin CM, Krauss SA, Szeto L, Golomb HM, Hoffman PC (2000) A phase I study of STEALTH cisplatin (SPI-77) and vinorelbine in patients with advanced non small-cell lung cancer. Clin Lung Cancer 2: $128-132$

Wozniak AJ, Crowley JJ, Balcerzak SP, Weiss GR, Spiridonidis CH, Baker LH, Albain KS, Kelly K, Taylor SA, Gandara DR, Livingston RB (1998) Randomized trial comparing cisplatin with cisplatin plus vinorelbine in the treatment of advanced non-small-cell lung cancer: a Southwest Oncology Group study. J Clin Oncol 16: 2459-2465 